Society against societies: the possibility of transcultural criticism $^{1}$ Samuel Clark

Penultimate draft; for final version, see Res Publica 13(2007): 107-125

It is often supposed that we should not impose 'our' constructions, understandings and values on 'other' cultures. Sometimes, this is because it is thought that to do so is analogous, or even causally related, to tyrannical imperial and colonial politics, and therefore morally bad in the same way that they are morally bad. I shall approach this claim via a further, and in some ways stronger claim, that there is something epistemically as well as morally problematic about transcultural understanding. Specifically, that it is impossible for (meaningful) moral criticism, which requires understanding, to reach outside 'our' culture.

The wider context of this idea is the question of global justice: What is the practical, moral and epistemic significance of boundaries between cultures, societies, nations or states? ${ }^{2}$ My target here is one of several positions which claim that the scope of justice is, or should be, restricted by one of these kinds of boundary. Realists such as Kenneth Waltz, for instance, have argued that the only duty of a state in the international system is to pursue its own strategic interests, and therefore that state boundaries are the limit of international morality ${ }^{3}$. Nationalists such as David Miller, for another instance, argue that the demands of (at least) distributive justice apply only within the nation understood as a distinctive, valuable, and necessarily sizelimited form of human association ${ }^{4}$. The position I criticise here, particularism, also claims that the scope of justice is limited, in this case by a shared culture which makes moral understanding and criticism possible. It is importantly distinct from realism and

\footnotetext{
${ }^{1}$ This paper draws on Samuel Clark, Living Without Domination: The possibility of an anarchist utopia (Aldershot: Ashgate, forthcoming 2007), chapter 2. I would like to thank Gideon Calder, and two anonymous referees for Res Publica, for their helpful comments on an earlier draft.

${ }^{2}$ For more on boundaries, see Onora O'Neill, 'Identities, Boundaries and States' in Bounds of Justice (Cambridge: CUP, 2000), pp. 168-85. For the global justice debate in general, Simon Caney, Justice Beyond Borders: A global political theory (Oxford: OUP, 2006).

${ }^{3}$ Kenneth Waltz, Theory of International Politics (Reading Mass.: Addison Wesley, 1979).

${ }^{4}$ David Miller, On Nationality (Oxford: Clarendon Press, 1995); Miller, 'Bounded Citizenship' in Citizenship and National Identity (Cambridge: Polity, 2000), pp. 8196.
} 
nationalism, however, in that it grounds that claim on epistemic rather than on normative or practical arguments. For the particularist, moral knowledge, the normativity of morality, and the possibility of moral criticism, all derive from the shared meanings generated by culture. So, criticism cannot reach across boundaries between cultures, because there is no substrate of shared meaning by which intercultural criticism could be sustained. My analysis and criticism of this position focusses especially on work by Michael Walzer, as perhaps the most prominent modern particularist.

In Spheres of Justice ${ }^{5}$, Walzer offers an account of the nature and scope of justice which is quite distinct from familiar egalitarian, desert-based and rights-based theories. His account is pluralist in three linked senses. First, justice is not universal either in space or in time, but is a local and temporary creation of particular political communities. Second, there are multiple kinds of good, each with its own criteria of just distribution deriving from how a particular community understands that good. At least for modern liberal societies, the goods are security and welfare, money and commodities, office, hard work, free time, education, kinship and love, divine grace, recognition, and political power. Third, there is no underlying, unifying or fundamental principle which either determines justice for all communities, or entails a just distribution of all goods. Justice is grounded differently for different communities. That is, the Walzer of Spheres of Justice is an anti-universalist about justice, an anti-monist about the good, and an anti-foundationalist about justification. Walzer calls the theory of justice which he derives from these basic commitments complex equality: it is satisfied, and a community is therefore just, when each good is distributed according to its own, distinctive criteria in its own sphere, and when advantage in any one sphere does not translate into advantage in any another. So, for

\footnotetext{
${ }^{5}$ Michael Walzer, Spheres of Justice: A defence of pluralism and equality (New York: Basic Books, 1983). See also Walzer, Interpretation and Social Criticism (Cambridge Mass.: Harvard University Press, 1987). Walzer's views have changed somewhat since the publication of Spheres of Justice. In Thick and Thin: Moral Argument at Home and Abroad (Notre Dame: University of Notre Dame Press, 1994), Walzer wants 'to endorse the politics of difference and, at the same time, to describe and defend a certain sort of universalism' (p. x). However, since my target is a widely held view of which Spheres of Justice gives a particularly elegant statement, and not Walzer himself, this complication need not detain us here. The general account of Spheres of Justice which I give here draws on David Miller, 'Introduction' to David Miller \& Michael Walzer eds, Pluralism, Justice, and Equality (Oxford: OUP, 1995), pp. 1-16.
} 
instance, justice is achieved in the sphere of money, in 'our' liberal democratic community, when it is distributed according to skill and luck in the market, and when wealth cannot buy political power.

On the basis of this theory of justice, Walzer argues that only internal criticism is possible, and that since our only moral resources are in our shared 'social meanings ${ }^{6}$, the shared meanings and ways of life of others are neither available to us for comparison nor vulnerable to criticism from us. For Walzer, there is no transcultural point of view from which we could judge all, or even our own institutions: there cannot be a view from no culture ${ }^{7}$. All one can do is interpret to one's fellow citizens the world of meanings that we share ${ }^{8}$. So, all criticism of ways of life is internal criticism, which shows us that we are not living up to our own best understanding of justice. Social criticism must be connected criticism - a matter of expressing our own standards and highlighting our hypocrisy and failure to live up to them, not a matter of deriving prescriptions from universal axioms ${ }^{9}$. Comparison with some other social form is irrelevant to that task, and delusive in its pretence that we could stand back from our own and compare it with another's understanding. 'A given society is just if its substantive life is lived in a certain way - that is, in a way faithful to the shared understandings of [its] members ${ }^{10}$; it is unjust if not. It cannot be praised or condemned according to how it compares to values or understandings external to it. A caste society cannot be criticised for not living up to egalitarian ideals (nor vice versa). The moral and political understandings of other societies are not available to us: our political imaginations must be expanded, if at all, by the discovery and imaginative interpretation of our own best selves. The politics which Walzer uncovers and interprets for us is radically egalitarian and democratic, but his methodology is 'radically particularist', and so 'If such a society isn't already here -

\footnotetext{
${ }^{6}$ Walzer, Spheres of Justice, p. 9

${ }^{7}$ The allusion here is, of course, to Thomas Nagel, The View From Nowhere (Oxford: OUP, 1986).

${ }^{8}$ Ibid., p. xiv.

9 In The Company of Critics: Social criticism and political commitment in the twentieth century (New York: Basic Books, 1988), Walzer investigates some exemplary critics in this style, including, for instance, George Orwell, Martin Buber, Albert Camus and Herbert Marcuse.

${ }^{10}$ Walzer, Spheres of Justice, p. 313.
} 
hidden, as it were, in our concepts and categories - we will never know it concretely or realize it in fact. ${ }^{, 11}$

Walzer's argument has been criticised on the grounds that the social meanings of at least some goods do not uniquely determine criteria for their distribution. Brian Barry $^{12}$, for instance, argues that the meaning of money for us is just that it is an anonymous claim on other goods and services, and that meaning entails no particular criteria for just distribution. Ronald Dworkin ${ }^{13}$ further argues that in our tradition, not only do the social meanings of goods not uniquely determine justice in their distribution, but Walzer's appeal to social meaning is self-effacing. Our tradition is that the just distribution of goods, for instance medical care, is a matter of continuing argument rather than consensus; and that argument is explicitly foundationalist. Equality, need, desert or rights, rather than the meaning of goods, determine justice. So, if Walzer really wants to rely on shared meanings, he should accept that shared meanings are the wrong place to look for a theory of justice.

This paper adopts a different critical strategy. I shall assume, for the sake of argument, that justice does arise from the shared social meanings of goods, and that those goods have a sufficiently determinate shared meaning to give concrete distributive prescriptions; and then show that, even given these assumptions, Walzer's particularism does not follow. Even if justice is a creation of culture, it is not therefore particular or bounded: that the grounds of justice are to be found in culture does not entail that the scope of justice is limited. I shall make a kind of negative transcendental argument for this conclusion: the conditions of possibility of Walzer's shared meanings do not respect his community boundaries; so, if there are shared meanings at all, Walzer's particularism is refuted.

Walzer's argument requires that there are such things as 'shared meanings' which can be interpreted for critical and political purposes. The possibility of shared meanings depends on the fact of human society: a permanently isolated human could not share meaning. Walzer's argument further depends on a particular understanding of the sharing of meaning, and therefore of society. For Walzer, we share some set of meanings (democratic, pluralist, complex-egalitarian), and they share some different

\footnotetext{
${ }^{11}$ Ibid., p. xiv.

12 Brian Barry, 'Spherical Justice and Global Injustice' in Miller \& Walzer eds, Pluralism, Justice, and Equality, pp. 67-80.

${ }^{13}$ Ronald Dworkin, 'What Justice Isn't' in A Matter of Principle (Oxford: Clarendon Press, 1986), pp. 214-20.
} 
set, such that our goods are different and incommensurable. There must be at least two distinct human societies, and therefore at least two distinguishable sets of meanings, if there are to be examples of human sociability which are not available to us for comparison and example. It seems obvious, of course, that this is the case: I shall argue that it is not. Although individual humans are certainly different from one another, and certainly encounter mutual difficulties in understanding, there are no discrete, mutually exclusive societies to make discrete, incommensurable meanings possible. Walzer's argument fails, because its foundation is a faulty theory of society. I shall now set out and argue for the alternative theory which refutes Walzer's.

\section{A theory of society ${ }^{14}$}

A theory of society could be an attempt at a complete general account, or even a complete explanation of society, but I do not intend anything so ambitious here. As I discuss further under 'Culture and shared meaning', Walzer's particularism is best understood as part of the interpretative turn in the human sciences, which (putting the point crudely) tried to make meaning rather than causal explanation central to anthropology, political science, psychology, historiography and philosophy. Part of what the partisans of this shift wanted to do was to turn away from what they regarded as scientism, reductionism and positivism in favour of interpretation of meaning, situated investigation, and participation in ongoing practices and narratives ${ }^{15}$.

In line with my strategy of assuming most of Walzer's theory for the sake of argument, I do not intend to reject this style of working, nor therefore to take on a reductive project. I do not claim that the features of human sociability on which I focus are real, fundamental or deep in comparison to other features, nor that they are finally explanatory. In particular, I claim only that society makes shared meaning possible, not that shared meaning is an epiphenomenon of society. Shared meanings may well have independent causal powers (I do not need to consider whether or not

14 The theory I develop here is deeply indebted, as ongoing citation should make clear, to the work of Eric R. Wolf in Europe and the People Without History (Berkeley: University of California Press, 1997) and Michael Mann in Sources of Social Power (2 vols, Cambridge: Cambridge University Press, 1986 \& 1993).

${ }^{15}$ See David R. Hiley, James F. Bohman \& Richard Shusterman eds, The Interpretive Turn: Philosophy, Science, Culture (Ithaca: Cornell University Press, 1991); and, more generally, Ian Shapiro, The Flight From Reality in the Human Sciences (Princeton: Princeton University Press, 2005). 
they do, here). My argument is that the possibility of shared human meaning depends on human society: the possibility of shared meaning has society as a necessary, but perhaps not a sufficient, condition. The truth of a theory of society which makes Walzer's appeal to incommensurable meanings impossible therefore refutes his theory. To repeat, the strategy can be understood as a kind of negative transcendental argument: the conditions of possibility of shared meaning have anti-particularist consequences. Now that I have described what kind of theory is presented here, we can proceed to the theory itself.

Humans, pursuing a wide variety of interests, create, discover, modify and destroy social organisations. These organisations consist of networks of humans interacting in modes including cooperation, negotiation, production, exchange, coercion, hierarchy, friendship, enmity, violence, ritual and play. Interactions are carried out both face-to-face and through various media. Almost all humans are involved in many such networks, in many roles, and these networks overlap, interpenetrate and sometimes include one another. Networks change in response to changes in or discoveries of interests, to the effects of other networks, and to changing environments and the opportunities and demands they create.

Although it is perhaps possible that some humans could organise themselves into a single, unified and discrete organisation in and through which they carried out all of their social activity, this has never in fact happened. There are, and have been, no social totalities: 'We can never find a single bounded society in geographical or social space.' 16 'Society' names not a kind of organism, but an activity, apparently natural for humans as for many other animals. It importantly involves the cooperative creation and assignment of capacities (especially capacities to attain and distribute goods, organise cooperation, manage conflict, dominate others and resist domination). Human social life consists of 'overlapping networks of social interaction' which are also 'organisations, institutional means of attaining human goals' ${ }^{17}$.

Human social life has historically been both various, and sometimes quite stable, and I therefore use 'social form' as a term of convenience for any relatively stable and persistent bundle of networks, where it is useful to have a shorthand for such a distinguishable way of life. However, I do not intend to imply that any such

\footnotetext{
${ }^{16}$ Mann, Sources of Social Power, vol. 1, p. 1.

${ }^{17}$ Ibid., p. 2.
} 
social form is a fully discrete society, nor that it is a higher-order entity than the individuals and networks of which it consists.

Human society depends on general human capacities ${ }^{18}$. Humans share a number of such capacities, including capacities to learn and use language; to create, understand and use symbols; to act on reasons and explain (or conceal) those reasons; to have and act on a variety of emotional and dispositional states apart from reasons; to make and use tools; to create and challenge hierarchies; to act in, and by using, social networks; to make decisions; to be selfish or altruistic; to be violent or friendly; to perceive oneself as a self in the context of other selves; and to create, internalise, perform and find significance in rituals. Many of these capacities are shared in some form or degree by our close relatives, including Chimpanzees, Gorillas, Orang-Utans and other primates. For the same reason that we are a particular kind of evolved creature, humans also share some general interests ${ }^{19}$. They include interests in food, shelter, company, continued life, the respect of peers and the absence of (threatened or actual) violence. These interests can be trumped by other, often socially constructed demands, but are typical of humans and very strong. So, an appeal to such interests, to a stranger, can often be effective. Individual humans' interests can clash at least because they sometimes differ, and because although you and I both have interests in food, for instance, our interests clash in conditions of scarcity. ${ }^{20}$

If this theory that human society consists in overlapping and interpenetrating networks, not discrete and mutually exclusive societies, is true, then Walzer's theory (and the similar theories and beliefs of which his are an exemplar) cannot get off the ground. Although we do share meaning, the possibility of doing so is dependent on society, and society is not such that it could make one set of meanings for us, and

\footnotetext{
18 'All human beings have various generic capacities to acquire skills, which, though they differ in their specific forms from tribe to tribe, are nevertheless of the same general kind'. Rom Harré, Social Being (2 ${ }^{\text {nd }}$ edn, Oxford: Blackwell, 1993), p. 3.

${ }_{19}$ I intend 'interests' here to refer to common necessary conditions of not being harmed or suffering deprivation, consequent on our nature as evolved creatures in a unfriendly physical world (compare David Wiggins's analysis of 'needs': 'Claims of Need' in Needs, Values, Truth: Essays in the philosophy of value ( $2^{\text {nd }}$ edn, Oxford: Blackwell, 1991), pp. 1-57). I do not intend any particular moral claim.

20 This paragraph sets out a conception of human nature which is minimalist by comparison with many other such conceptions. It is minimalist in particular because I do not suggest that it stands as a norm for humans: it is an account of (some of) the (biological and cognitive) capacities which make society possible, not an ideal to live up to.
} 
another incommensurable set for them. However, we still need to show that this network theory is true. I shall argue for it by contrasting it with a familiar, alternative way of characterising human society, on which Walzer's theory would work.

\section{Against social totalities}

To the extent that it is not simply a careless way of talking or a traditional working assumption, the assertion of the existence of social totalities is the claim that humans are typically found in discrete, unified social 'boxes', which have boundaries, subsystems, levels or dimensions, and perhaps an internal 'evolutionary' dynamic, and within which the society's members share meaning which is inaccessible to those outside. On this view, social change and conflict can be divided into endogenous and exogenous types, human behaviour can be explained by reference to 'social structure as a whole ${ }^{21}$, and there are two distinct, but analogous, problems for political philosophy: one about how individuals within a society should organise themselves, and another, at a 'second level', about how distinct societies should organise their interrelations. These problems have been thought sufficiently analogous by Kant and by Rawls, for instance, that they have attempted to answer both with the device of a hypothetical contract ${ }^{22}$.

It is unclear to me what these claims could be except empirical ones about how humans now, or always, live ${ }^{23}$. But they are false. As Michael Mann argues:

Empirical proof can be seen in the answer to a simple question: In which society do you live? Answers are likely to start at two levels. One refers to national states: My society is "the United Kingdom," "the United States," "France," or the like. The other is broader: I am a citizen of "industrial society" or "capitalist society" or possibly "the West" or "the Western alliance." We have a basic dilemma - a national state society versus a wider "economic society." For some important

\footnotetext{
${ }^{21}$ Mann, Sources of Social Power, vol. 1, p. 1-2.

${ }^{22}$ Kant, 'Perpetual Peace: A philosophical sketch' in Hans Reiss (ed.), Political Writings, trans. H. B. Nisbet $\left(2^{\text {nd }}\right.$ edn, Cambridge: Cambridge University Press, 1991), pp. 93-130. Rawls, The Law of Peoples with The Idea of Public Reason Revisited (Cambridge Mass.: Harvard University Press, 1999).

${ }^{23}$ Perhaps the point should be put as follows: if they are not such empirical claims, it is very unclear why we should pay any attention to them, or, in particular, why we should suppose that anything follows from them for our epistemic and critical capacities.
} 
purposes, the national state represents a real interaction network with a degree of cleavage at its boundaries. For other important purposes, capitalism unites all three into a wider interaction network, with cleavage at its edge. They are both "societies." Complexities proliferate the more we probe. Military alliances, churches, common language, and so forth, all add powerful, sociospatially different networks of interaction. We could only answer after developing a sophisticated understanding of the complex interconnections and powers of these various crosscutting interaction networks. The answer would certainly imply a confederal rather than a unitary society. ${ }^{24}$

The argument so far is that we in particular do not live in unitary and discrete societies, despite the enormous power and reach of modern states which try to divide us up into such boxes. This is shown, especially, by the overlapping coexistence of two different kinds of social network, national states and capitalism, and emphasised by the range of other, sociospatially different networks in which we are also involved. Mann continues by arguing that this confederal situation is typical of human life, not just of our life. Empires, trade-and-cultural networks, world religions, all cut across one another: 'Overlapping interaction networks are the historical norm ... The forms of overlap and intersection have varied considerably, but they have always been there. ${ }^{25}$ It is not only we who live in a confederal situation: most humans have always lived like that. The belief in social totalities badly misrepresents the current and historical experience of social humans, and should therefore be abandoned. In its place, we need to recognise the typical human situation of being involved in multiple, cross-cutting networks of interaction, with particular and different spatial and social reaches, tactics and dynamics. Humans 'are social, but not societal, animals' ${ }^{26}$.

General names for social totalities like 'culture', 'nation' or 'tribe', and particular ones like 'Iroquois, Greece, Persia, or the United States ${ }^{27}$ distort our perception of human social organisation. They need not therefore be abandoned (they are occasionally useful), but they obscure complex and cross-cutting inter-relations, and must not be hypostasised.

\footnotetext{
${ }^{24}$ Mann, Sources of Social Power, vol. 1, p. 16.

${ }^{25}$ Mann, Sources of Social Power, vol. 1, p. 16; p. 17.

${ }^{26}$ Ibid., p. 14.

${ }^{27}$ Wolf, Europe and the People Without History, p. 7.
} 


\section{Society against societies}

I have mapped human society as a notably flat landscape, without impermeable boundaries. Humans, pursuing various ends and interests, create, discover, modify and destroy social organisations, which are networks of humans interacting in various ways, and creating and assigning capacities. These networks overlap and interpenetrate one another. Networks change in response to changes in, or discoveries of, interests; to the effects of other networks; and to changing environments and the opportunities and demands they create. Humans do not organise themselves into unitary and discrete social totalities, but live in confederal social situations.

This refutes Walzer's claim that our only moral and critical resources are to be found in our discrete shared meanings, by showing that it relies on a faulty theory of society. Since there are no discrete societies, but only cross-cutting networks, there can be no such conflicts of incommensurable meaning between home and abroad, between $u s$ and them. The social meanings and forms of others are available to us for warning, emulation, criticism and utopian construction. I have not argued that humans never face each other across divides in understanding: that would be merely silly. I have argued that the divides do not separate us into discrete bodies of people who share meanings internally, but have no access or understanding externally. Each of us has many networks in which we share meaning, and many boundaries at which we currently do not. I say currently, because humans clearly do have capacities to cross such boundaries: we have the capacity to create shared meaning with strangers. If we did not, it is difficult to see how the shared meanings to which Walzer appeals could have come about, since all of us frequently meet and deal with strangers, beginning with our parents. That is: the capacity which makes Walzer's shared meanings possible also makes his mutually incomprehensible bodies of meaning-sharers impossible. Humans can only share meaning because we can reach across divides in understanding, and if there could be permanent strangers, there could not be communities of meaning-sharers. There is no permanent 'we' and incomprehensible 'they'.

To recap: I have argued that the possibility of shared meaning depends on society; that society is not such as could support the existence of incommensurable meanings; and further, that the very social capacity which creates shared meanings makes permanently separate societies of $u s$ and them impossible. 


\section{Culture and shared meaning}

It may be suggested that I have missed the point. Walzer is talking about cultures, not societies, as his appeal to shared meaning indicates. As I have already suggested, Walzer is part of the large post-interpretive turn camp - he is to political philosophy what Jerome Bruner is to psychology ${ }^{28}$ - and his central focus is on the interpretation of meaning: 'One characteristic above all is central to my argument. We are (all of us) culture-producing creatures; we make and inhabit meaningful worlds. ${ }^{29}$ In making this central commitment, Walzer is following the anthropologist (and his late colleague in the Institute of Advanced Studies at Princeton) Clifford Geertz in believing that 'man is an animal suspended in webs of significance he himself has spun' and taking 'culture to be those webs, and the analysis of it to be therefore not an experimental science in search of law but an interpretive one in search of meaning, ${ }^{30}$. Walzer's interpretation of shared meanings and consequent critical practice are interpretive, and he has taken to heart the idea that there is something especially difficult about interpretation abroad, as opposed to at home. This is not a counterargument to what I have claimed, unless we are prepared to suppose that culture is independent of the social interactions of the people who are its carriers and makers. In the absence of such an claim (which would surely be bizarre), the fact that humans do not live in discrete, mutually exclusive societies means that their cultures are not discrete or mutually exclusive either.

However, the point about culture, and Geertz's semiotic understanding of it in particular, is important. Walzer has adopted Geertz, and his work does appear to

${ }^{28}$ See for instance Jerome Bruner, Acts of Meaning (Cambridge Mass.: Harvard University Press, 1990).

${ }^{29}$ Walzer, Spheres of Justice, p. 314.

30 Geertz, 'Thick Description: Toward an interpretive theory of culture' in The Interpretation of Cultures (London: Fontana Press, 1993), pp. 3-30. p. 5. Walzer explicitly makes reference to Geertz and to his notion of thick description in Thick and Thin, p. xi n. 1. The claim that mutual human understanding must be interpretive rather than (what is called) naturalistic will be most familiar, to philosophers, from the work of Charles Taylor: see, for instance, 'Interpretation and the Sciences of Man' in Philosophy and the Human Sciences: Philosophical papers 2 (Cambridge: Cambridge University Press, 1985), pp. 15-57. It is therefore worth noting that Geertz is not as sympathetic to Taylor's work as might, at first glance, be expected: see 'The Strange Estrangement: Charles Taylor and the natural sciences' in Available Light: Anthropological reflections on philosophical topics (Princeton: Princeton University Press, 2000), pp. 143-59. 
support particularist claims: but, I shall argue, it does not (and, consequently, anthropological theory does not support the particularist theories I am using Walzer to exemplify).

Geertz is importantly a deflator of the pretensions of scientific anthropology. It had been believed that one could (for instance) travel from England to the Sudan, describe the social form of the Nuer as a 'segmentary lineage', and thereby understand the Nuer themselves (this is of course a pastiche, but it will do to make the point). The understanding gained would help one to predict Nuer behaviour, to bring them under 'rational' adminstration as part of an empire, and to place and explain them in a wider taxonomy of human social forms and their historical development (as 'primitive', as an acephalous tribe, as operating a certain kind of kinship system). Geertz argues that, on the contrary, understanding the Nuer or anyone else is an intensely difficult and never complete process of interpretation. Encounters with others are attempts at reading: 'Doing ethnography is like trying to read (in the sense of "construct a reading of") a manuscript - foreign, faded, full of elipses, incoherencies, suspicious emendations, and tendentious commentaries. ${ }^{31}$ What one reads or interprets is always already an interpretation. There is no bedrock of uninterpreted data: the ethnographer is always 'explicating explications, ${ }^{32}$.

Two things have lent themselves to misinterpretation of this argument. The first is that Geertz's examples are all, unsurprisingly, from ethnographic fieldwork. He describes, for instance, a complex 'confusion of tongues' between Jewish, Berber and French 'frames of interpretation' in Morocco, in 1912 (as reported to him in $1968)^{33}$. This may give rise to the thought - in my view, has given rise to it - that there is something especially difficult about going abroad and attempting to understand them, or in attempting to translate between Jewish, Berber and French self-understandings, but that no such difficulty applies when we are at home, or when Jews, Berbers or French people talk amongst themselves. The second thing which lends itself to misunderstanding is Geertz's emphasis on the incompleteness of interpretation. There is no final reading of culture, only an ongoing process of rereading, of attempting to reunderstand what is already understood. This may give

\footnotetext{
${ }^{31}$ Geertz, 'Thick Description', p. 10.

${ }^{32}$ Ibid., p. 9.

${ }^{33}$ Ibid.
} 
rise to the thought that interpretation (when abroad) cannot be done at all, because it cannot be finished ${ }^{34}$.

Neither of these thoughts seems to me to do justice to what Geertz says. Geertz is importantly influenced by the later Wittgenstein ${ }^{35}$, and his method is best understood as an application and development of Wittgenstein's approach to language. Culture, like language, is public, and understanding it does not consist in discovering its logical form or subsuming it under a concept ('segmentary lineage'). It consists in learning to go on in the right way. So, 'finding our feet' in someone's culture is a matter of 'seeking, in the widened sense of the term in which it encompasses very much more than talk, to converse with them, a matter a great deal more difficult, and not only with strangers, than is commonly recognised ${ }^{36}$. Geertz's point is not that there is something fundamentally problematic about conversing when abroad, but that there is something mysterious about conversing at all. Nonetheless, we do manage to converse. 'The famous anthropological absorption with the (to us) exotic [is] essentially a device for displacing the dulling sense of familiarity with which the mysteriousness of our own ability to relate perceptively to one another is concealed from us. ${ }^{37}$

So: Geertz's point is not that, when we venture abroad, we leave behind a people and a culture which we understand, and encounter a people and a culture which is and must remain wholly opaque to us. It is that our interpretations of one another are always tentative and ongoing, wherever we are: 'Foreignness does not

\footnotetext{
${ }^{34}$ We might be reminded of the David Lodge character who plans 'a series of commentaries on Jane Austen which would work through the whole canon, one novel at a time, saying absolutely everything that could possibly be said about them. The idea was to be utterly exhaustive, to examine the novels from every conveivable angle, historical, biographical, rhetorical, mythical, Freudian, Jungian, existentialist, Marxist, structuralist, Christian-allegorical, ethical, exponential, linguistic, phenomenological, archetypal, you name it; so that when each commentary was written there would be simply nothing further to say about the novel in question.' Changing Places (London: Penguin, 1975), p. 44.

${ }^{35}$ See 'Passage and Accident: A life of learning' in Available Light, pp. 3-20. For consideration of the application of Wittgenstein to the human sciences, see for instance Peter Winch, The Idea of a Social Science and its Relation to Philosophy (London: Routledge, 1958); David Bloor, Wittgenstein: A social theory of knowledge (London: Macmillan, 1983).

${ }^{36}$ Geertz, 'Thick Description', p. 13, my emphasis.

${ }^{37}$ Ibid., p. 14.
} 
start at the water's edge but at the skin's... The wogs begin long before Calais. ${ }^{38}$ The anthropological exotic (apart from its intrinsic interest) is a way of bringing home to ourselves both the difficulty and the surprising possibility of mutual understanding. Geertz's interpretive anthropology, far from supporting the Walzerian claim that understanding and critique cannot leave home, emphasises the fact that, necessarily, we continuously cross our own boundaries, encounter strangers, and half-successfully engage with them.

\section{Epistemic colonialism}

I have already pastiched one kind of anthropology, which attempts to understand others by discovering the logical form of their culture, or by subsuming it under abstract concepts. This kind of anthropology certainly was involved in colonial projects: E. E. Evans-Pritchard's pioneering work with the $\mathrm{Nuer}^{39}$, for instance, was involved with British colonialism. When Evans-Pritchard lived with and studied them in the 1930s, the Nuer were a group of perhaps two or three hundred thousand people living around the Nile, in what was then the Anglo-Egyptian Sudan, in East Africa. At that time, they were having to deal rapidly with invasion by British military forces and the consequent imposition of new administrative and political institutions, including, for instance, a colonial governor who argued that the Nuer 'are slow to appreciate the blessings of European civilization and the benefits arising from an ordered administration of their country. Although this outspoken self-consciousness was bound to lead to conflicts, it must be admitted that the personal qualities of the people that caused these conflicts are of a kind that ought to be cultivated and guided rather than blamed and suppressed. ${ }^{40}$ Evans-Pritchard "was profoundly aware of "the colonial encounter" and was, in fact, part of it ${ }^{41}$, having been commissioned by the

\footnotetext{
${ }^{38}$ Geertz, 'The Uses of Diversity' in Available Light, pp. 68-88. p. 76.

${ }^{39}$ Evans-Pritchard, The Nuer: A description of the modes of livelihood and political institutions of a Nilotic people (Oxford: Clarendon Press, 1940); 'The Nuer of the Southern Sudan' in Meyer Fortes \& Evans-Pritchard (eds.), African Political Systems (London: Oxford University Press, 1940), pp. 272-96; Kinship and Marriage Among the Nuer (Oxford: Clarendon Press, 1951); Nuer Religion (Oxford: Clarendon Press, 1956). On the vast literature sparked by Evans-Pritchard's work, see Sharon E. Hutchinson, Nuer Dilemmas: Coping with money, war, and the state (Berkeley: University of California Press, 1996).

${ }^{40}$ Diedrich Westermann, Introduction to Ray Huffman, Nuer Customs and Folk-Lore (London: Frank Cass \& Co., 1970; first published 1931), pp. v-xi. p. v.

${ }^{41}$ Hutchinson, Nuer Dilemmas, p. 30.
} 
colonial government in the Sudan to investigate the Nuer. We should be wary of ascribing crudely colonial motives to him personally, but should be aware that at least part of the point of his investigations was to render the Nuer transparent to bureaucratic surveillance and thereby take them under imperial state control.

So, one sort of attempt to understand others - the Nuer, in this case - is clearly related to one sort of colonial project. The two are also analogous, at least in that both are one-sided and probably self-interested (they involve the imposition of structures of understanding or control by one side on the other, apparently for purposes of exploitation). Perhaps the thinking which leads to positions like Walzer's is this: (attempted) understanding of other cultures was part of morally disastrous colonial projects; we should never have undertaken such projects (we should have stayed at home); critiques of this kind of understanding (such as Geertz's) are therefore critiques of 'going abroad' in understanding, and of the consequent attempt to criticise and transform local arrangements in terms of the putative blessings of European civilization'. However, as I argued above, this misunderstands Geertz's critique. We can certainly reject attempts to impose our own social arrangements on others, especially when doing so requires violence and oppression, but we are unwise to do so in terms of a rejection of the possibility of understanding strangers sufficiently that we could share goods with them. Not all transcultural understanding takes that form; if Geertz is right, no genuine understanding of humans could take it, for reasons analogous to Wittgenstein's reasons for denying the possibility of private language (although we should note that rendering local, opaque systems of punishment, land tenure and measurement transparent to bureaucratic surveillance has historically been an effective method of control, and therefore that something is apparently being understood in such cases ${ }^{42}$ ).

\section{Conclusion: the ethics of engagement with strangers}

I began by setting out a view about the possibility of transcultural understanding and criticism, using Michael Walzer's Spheres of Justice as a exemplar. I have shown that it depends on an untenable account of the nature of human society, and therefore that it ought to be abandoned. I then went on to consider the relations between this view and Clifford Geertz's influential account of the interpretation of culture, and

${ }^{42}$ See James C. Scott, Seeing Like a State: How certain schemes to improve the human condition have failed (New Haven: Yale University Press, 1998). 
distinguished two putative kinds of understanding, only the first of which seems linked or analogous to colonial projects. Where does this leave us in relation to the worry I raised at the start of this paper, that there is something immoral about understanding others in our own terms? I suggest that it leaves us with the (obvious?) thought that it depends very much on what we mean by 'understanding'. There is a sort of (attempted) understanding of others, which is exemplified by the colonial practice of investigation for purposes of surveillance and exploitation, and which is, at best, morally tainted by its association with oppression. However, there is another sort of understanding, exemplified by the interpretive practice urged by Geertz, on which the process of coming to converse with strangers is difficult, never finished, and vital. This does not seem morally problematic: indeed, it seems to me to be morally required. It is certainly pragmatically required, given that meeting strangers is not something we can avoid.

This second kind of understanding does not involve (merely) imposing our own categories on others who have different understandings of themselves: it involves 'finding our feet' with others. That is, it involves being able to go on in a practice (or according to the rules of some game) which has become shared. Peter Winch has argued that 'Seriously to study another way of life is necessarily to seek to extend our own - not simply to bring the other way within the already existing boundaries of our own. ${ }^{43}$ I claim that seriously to attempt to understand another person is to change oneself, because the actual world does not consist of discrete societies or cultures which meet and clash at their boundaries. It consists (in part) of social and variously cultured individual humans who must unendingly interpret one another. This process is not (cannot be) one-sided. Mutual criticism, including self-criticism, must sometimes be a part of meeting and interpreting strangers, and part of the importance of the shock of the different which anthopological data provides is that it is also an ethical shock. Our encounters with strangers who need not remain strangers can remind us of the basic ethical truth ${ }^{44}$ that our ways are not inevitable, and could be mistaken. That possibility is an important basis for (moral, social, political) criticism,

\footnotetext{
43 'Understanding a Primitive Society' in Bryan R. Wilson ed., Rationality (Oxford: Basil Blackwell, 1970), pp. 78-111. p. 99.

${ }^{44}$ I have not intended to assert any meta-ethical theory. If anyone is troubled by the phrase 'basic ethical truth', she should substitute 'good advice'.
} 
and we would be ill-advised in practice, as well as mistaken in theory, to rule it out of court as not part of 'our' shared meanings.

The central point I have made against particularism, as exemplified by Walzer, is that we can get to a kind of universalism about justice without assuming the possibility of a view from nowhere. The facts of human sociability mean that understanding can start from where we are, and have no need to stop at community boundaries. That is, the conditions of possibility of the shared meanings to which Walzer appeals have anti-particularist consequences. The point of later sections has been to argue that we are not faced with a choice between, on one hand, staying at home and leaving other cultures alone in their incomprehensible (to us) shared meanings; and, on the other, becoming imperialists. The third, morally and practically vital option is engagement with strangers, and it need not stop at any impermeable cultural boundary, because there are no such boundaries.

A final recap: I have argued that, even if we accept a great deal of the interpretive approach to philosophical, anthropological and other human science practice in general, and Walzer's derivation of justice from the social meaning of goods in particular, we can nonetheless resist Walzer's anti-universalism. Even if justice must come from shared meaning, this does not entail that no transcultural criticism in the name of justice is possible, because the conditions of possibility of shared meaning - the facts of human sociability - make discrete, mutuallyincomprehensible cultures impossible. This leaves us with the difficult problem of coming to understand those who are currently strangers to us, rather than the congenial certainty of shared understanding at home; but it also defends the vital possibility of transcultural criticism. 